\title{
Conferencia internacional sobre tradición y humanismo*
}

El trabajo de estudiosos como Yves Congar, Alasdair MacIntyre, Josef Pieper y Edward Shils ha llamado la atención sobre la importancia fundamental de la tradición en todos los aspectos de la civilización. ¿Cómo nacen las tradiciones? ¿Cómo se desarrollan e interactúan unas con otras? Esta cuestión es de gran relevancia en la misión educativa de la Universidad de Dallas y del Instituto Tecnológico Autónomo de México.

El plan de estudios de la Universidad de Dallas, con su investigación sobre la manera en que Aristóteles responde a Platón, el cristianismo nace del judaísmo, Virgilio retoma a Homero, Tomás de Aquino sintetiza a Agustín y Aristóteles, los fundadores encuentran inspiración de los clásicos — por mencionar algunos ejemplos—, está formado en torno a la noción de tradición. El Departamento Académico de Estudios Generales del ITAM tiene un plan de estudios muy similar. México forma parte de la tradición occidental; pero el encuentro del imperio español con los pueblos indígenas de la región dio origen a una cultura distinta, cuya dinámica se resume a menudo con el término mestizaje. Por ello, el plan de estudios del Departamento de Estudios Generales culmina en la investigación de temas relevantes del México contemporáneo. El objetivo de la Conferencia es poner en diálogo estas dos tradiciones educativas, con sus semejanzas y diferencias, y examinar los mecanismos de la tradición misma.

\section{PHILIPP ROSEMANN}

Jefe del Departamento de Filosofía, Universidad de Dallas

* Traducción de Carlos Gutiérrez Lozano. 
CITAM Derechos Reservados.

La reproducción total o parcial de este artículo se podrá hacer si el ITAM otorga la autorización previamente por escrito. 